Original Article

\title{
Relationship among Ocular Diseases, Developmental Levels, and Clinical Characteristics of Children with Diplegic Cerebral Palsy
}

\author{
Ahmet Boyaci, MD ${ }^{1)^{*}}$, Ali Akal, MD ${ }^{2)}$, Ahmet Tutoglu, MD ${ }^{1)}$, Hasan Kandemir, MD ${ }^{3)}$, \\ Irfan Koca, MD ${ }^{4)}$, Ismail Boyraz, MD ${ }^{5}$, Esra Celen, MD ${ }^{1)}$, Ufuk OzKan, MD²) \\ 1) Department of Physical Medicine and Rehabilitation, Harran University Medical School: Yenisehir \\ Kampusu, Sanliurfa 63300, Turkey \\ 2) Department of Ophthalmology, Harran University Medical School, Turkey \\ 3) Child and Adolescent Psychiatry, Harran University Medical School, Turkey \\ 4) Department of Physical Medicine and Rehabilitation, Gaziantep University Medical School, Turkey \\ 5) Department of Physical Medicine and Rehabilitation, Abant Izzet Baysal University Medical School, \\ Turkey
}

\begin{abstract}
Purpose] The aim of this study was to evaluate the relationships among vision problems, developmental levels, upper extremity functions, and qualities of life of children with cerebral palsy (CP). [Subjects] The study included 32 children, aged 4-15 years, diagnosed with diplegic type CP. [Methods] Hand function was evaluated using the Manual Ability Classification System (MACS) and the Bimanual Fine Motor Function (BFMF) scale, and the severity of CP was assessed using the Gross Motor Function Classification System (GMFCS). The developmental and mental capabilities of the children were evaluated using the Ankara Developmental Screening Inventory (ADSI) or the WISC-R test. An oculomotor examination was conducted for all patients. [Results] Positive correlations were found between GMFCS and BFMF, GMFCS and MACS, and MACS and BFMF scores ( $\mathrm{r}=0.636$; $\mathrm{r}=0.553 ; \mathrm{r}=0.718$, respectively). Significant correlations were found between upper extremity function, the severity of $\mathrm{CP}$, the quality of life, and the general developmental level. There was no significant correlation between ocular disorders and clinical characteristics. [Conclusion] GMFCS, MACS, and BFMF may be useful for defining the functional status of children with $\mathrm{CP}$, as they are easy, practical, and simple classification scales that conform to each other.

Key words: Gross motor function, Ocular disorders, Cerebral palsy
\end{abstract}

(This article was submitted Apr. 3, 2014, and was accepted Apr. 28, 2014)

\section{INTRODUCTION}

Cerebral palsy (CP) is a chronic, non-progressive clinical disease characterised by movement and posture impairments in children which is associated with permanent brain damage occurring in the perinatal or natal period ${ }^{1)}$. The patient may be affected by motor, tonus and posture disorders as well as a wide spectrum of problems associated with cerebral dysfunction such as learning difficulties, autonomic dysfunction, epilepsy, mental retardation, and sight and hearing problems ${ }^{2}$. The prevalence of CP in Turkey has been stated as 4.4 per 1,000 live births ${ }^{3)}$.

The most frequently seen type of CP in the Turkish population is diplegic $\mathrm{CP}$, and in $71.6 \%$ of these cases there is a history of prematurity ${ }^{3)}$. Spastic diplegia may be seen in

*Corresponding author. Ahmet Boyaci (E-mail: drboyaci@, hotmail.com)

(C2014 The Society of Physical Therapy Science. Published by IPEC Inc. This is an open-access article distributed under the terms of the Creative Commons Attribution Non-Commercial No Derivatives (by-ncnd) License $<$ http://creativecommons.org/licenses/by-nc-nd/3.0/>. both term and pre-term infants. In pre-term diplegic CP patients there is often a relationship with periventricular leukomalacia. Lower extremity involvement is more evident and patients have relatively better hand functions. According to the severity of the effect, advanced function loss in the upper extremity may be associated with the degree of spasticity, the presence of contracture, sensory loss or mental level ${ }^{4}$.

Ophthalmological problems are seen in $50-90 \%$ of CP patients $^{5-7)}$. Within the CP types, it has been reported that ophthalmological problems occur more often in diplegic type spastic $\mathrm{CP}^{6-8)}$. Refractive errors and strabismus are the most often seen ophthalmological problems in $\mathrm{CP}^{5-7}$ ). In a study evaluating the relationship between CP etiology and ocular and visual diseases, it was reported that particularly for patients with diplegic and triplegic $\mathrm{CP}$ with positive neuroradiological findings together with pre-term patients with low birth-weight, there is a need for an ophthalmological examination as early as possible ${ }^{9}$.

In a study which evaluated the hand functions using the Manual Ability Classification System (MACS) and the Bimanual Fine Motor Function (BFMF) scale, and the severity 
of CP with the Gross Motor Function Classification System (GMFCS), it was reported that in the evaluation of the hand functions of children with CP, the MACS and BFMF scales are consistent with each other and with the $\mathrm{GMFCS}^{10)}$. Ocular diseases which develop in CP patients and the developmental level can affect the functional level and quality of life of the patient. To the best of our knowledge, there is no study in the literature which has researched the relationship of ocular diseases or developmental level with upper extremity functions, daily living activities and quality of life of diplegic CP patients. Therefore this study aimed to evaluate the relationships among visual loss and developmental level, and upper extremity functions, daily living activities and quality of life.

\section{SUBJECTS AND METHODS}

The study group consisted of children with spastic CP who were admitted to the Physical Medicine and Rehabilitation Clinic between November 2013 and February 2014. The children included in the study were aged $4-15$ years and were diagnosed with diplegic $\mathrm{CP}$ according to the Swedish Classification ${ }^{11)}$. Patients with genetic or metabolic disease and those with a progressive neurological disease were excluded from the study. Approval for the study was granted by the Institutional Ethics Committee of Harran University, and written informed consent was obtained from all the parents of the patients.

For the determination of the developmental levels and mental capabilities of the children with CP, the Ankara Developmental Screening Inventory (ADSI), which has been tested for validity and reliability in Turkey, was used ${ }^{12-14)}$ The ADSI is a scale which can be used to assess children aged $0-6$ years to evaluate their communication-cognitive (CC), fine motor (FM), gross motor (GM), social skills-self care (SS-SC) and general development (GD) domains. The inventory consists of 154 items which are answered by the mothers, and responses are given as 'yes', 'no', or 'don't know'. The total score of the test reflects a subject's general developmental level. Those with an average two standard deviations below the norm are evaluated as developmentally retarded ${ }^{12)}$.

Children over 6 years of age were evaluated with the mental development WISC-R test. For children who could not be evaluated by the age-appropriate test as they were developmentally aged below 6 years, even though their chronological age was over 6 years, the ADSI was conducted.

The ophthalmological examinations of all the patients were conducted by the same ophthalmologist. Refraction errors, fundus examination, slit-lamp biomicroscopic examination, intraocular pressure measurement and oculomotor examinations were conducted. Compliance with the tests could not be achieved by any patient in assessment of visual acuity.

The GMFCS is a classification system which has been developed for children with CP. It is separated into 5 levels based on gross motor functions such as starting movements by oneself, sitting and walking. At Level I, in mobility within the community, disability is minimal or absent. At Level V, mobility is totally dependent, even with the use of assistive aids ${ }^{15)}$.

Hand functions of children with $\mathrm{CP}$ while they are holding objects in daily living activities were evaluated using the MACS scale. The aim is to define the hand performance. The MACS scale has 5 levels. At Level I, the patient can easily and successfully hold the objects. At Level V, an object cannot be held by the subject who has severely limited capability for any activity ${ }^{16)}$.

The BFMF was developed to evaluate the hand functions separately. It has 5 levels. At Level I, one hand can be used without any restriction and there is restriction in the fine motor skills of the other hand. At Level V, each hand can only hold at best ${ }^{17}$.

The Functional Independence Measure of children (WeeFIM) consists of 6 sub-categories. There are a total of 18 items: 6 items of self-care, 2 items of sphincter control, 3 items of transfer, 2 items of locomotion, 2 items of communication and 3 items of social cognition. Each item is scored from 1 to 7 , with 1 indicating full help and 7 indicating full independence. The total score can range from a minimum of 18 to a maximum of $126^{18)}$.

The Paediatric Quality of Life Scale (PedsQL) is a quality of life scale developed by Varni et al. to measure the quality of life of chidren and adolescents aged $2-18$ years ${ }^{19)}$. The areas of physical health, emotional functionality and social functionality are surveyed as the characteristics of health status defined by the World Health Organisation. Functionality at school is also surveyed. Scores are calculated for three domains. First, the total points (MTP), then the physical health total (PHTP), and finally the psychosocial health (PSHTP) are calculated from the item scores evaluating emotional, social and school functionality ${ }^{20)}$. The PedsQL is a quality of life scale consisting of 23 items which is suitable for use for the general population, such as in schools or hospitals, for both healthy and sick children and adolescents. The items are scored between 0-100. A response of never scores 100 , rarely 75 , sometimes 50 , often 25 and always, 0 . The higher the total score in the Ped$\mathrm{sQL}$, the better the quality of life is perceived in relation to health ${ }^{20)}$. Important properties of the PedsQL are that it is short and can be completed in 5-10 minutes, it can be conducted by a researcher and the scoring is easy ${ }^{20,21)}$. In the current study, the PedsQL children and parent forms were used. Previous studies have been demonsrated on the validity and reliability of the Turkish version of PedsQL for the 2-18 years age group ${ }^{22-24)}$.

Statistical analyses were carried out using SPSS 18.0 for Windows (PASW Statistics for Windows, SPSS Inc., Chicago, Illinois, USA). Spearman correlation coefficients were used to determine the relationships between variables. All demographic and quantitative data are expressed as mean \pm standard deviation (SD). Differences with $p$ values $<$ 0.05 were considered statistically significant and all results are expressed with a $95 \%$ confidence interval. The overall agreement between each GMFCS, MACS and BFMF values were analyzed using non-weighted Kappa statistics. Kappa values of $<0.20$ show poor agreement, $0.21-0.40$ fair, $0.41-0.60$ moderate, $0.61-0.80$ good, and $>0.80$ very good agreement ${ }^{25,26)}$. 


\section{RESULTS}

The study included 32 patients, 16 males and 16 females with a mean age of $90.50 \pm 31.60$ months (range, 50-172 months). Five (15.6\%) of the patients were pre-term and 27 (84.4\%) were term. Six (18.8\%) of the patients had a low birth-weight, $10(32.3 \%)$ had epilepsy and $14(43.8 \%)$ had a history of anoxia. Twenty-two $(68.8 \%)$ patients were deliv-

Table 1. Clinical characteristics of the patients

\begin{tabular}{lc}
\hline Characteristic & $\begin{array}{c}\text { Total, } \mathrm{n}=32 \\
\mathrm{n}(\%)\end{array}$ \\
\hline Developmental evaluation & \\
Normal & $14(43.8)$ \\
Retarded & $18(56.3)$ \\
WeeFIM total score, mean (SD) & $77.87 \pm 45.05$ \\
Child form of PedsQL, mean (SD) & \\
PedsQL total score & $40.25 \pm 33.96$ \\
PedsQL physical score & $40.40 \pm 33.25$ \\
PedsQL psychosocial score & $40.41 \pm 35.39$ \\
Parent form of PedsQL, mean (SD) & \\
PedsQL total score & $43.44 \pm 31.51$ \\
PedsQL physical score & $38.83 \pm 33.48$ \\
PedsQL psychosocial score & $45.22 \pm 31.89$ \\
GMFCS, levels & \\
1 & $16(50)$ \\
2 & $5(15.6)$ \\
3 & $1(3.1)$ \\
4 & $9(28.1)$ \\
5 & $1(3.1)$ \\
MACS, levels & $10(31.3)$ \\
1 & $18(56.3)$ \\
2 & $2(6.3)$ \\
3 & $1(3.1)$ \\
4 & $1(3.1)$ \\
5 & $18(56.3)$ \\
BFMF, levels & $8(25)$ \\
2 & $3(9.4)$ \\
3 & $2(6.3)$ \\
4 & $1(3.1)$ \\
5 & \\
\hline & \\
BF & \\
&
\end{tabular}

BFMF: Bimanual Fine Motor Function, GMFCS: Gross Motor Function Classification System, MACS: Manual Ability Classification System, PedsQL: Paediatric Quality of Life Scale, WeeFIM: The Functional Independence Measure of children ered by the normal vaginal route, and $10(31.3 \%)$ by caesarian section. The mean time of CP diagnosis was $12.96 \pm 9.41$ months and the mean time to starting rehabilitation was $21.93 \pm 19.16$ months. WeeFIM, PedsQL scores, developmental evaluation, and the distribution of patients according to GMFCS, BFMF and MACS are shown in Table 1.

Developmental evaluation of $25(78.1 \%)$ patients was made using the ADSI. Of these 12 (48\%) were aged below 6 years and 13 (52\%) could not perform the age-appropriate test even though they were aged over 6 years. The distribution of the patients according to the ADSI test is shown in Table 2. Of the 7 (21.9\%) patients assessed using the WISC$\mathrm{R}, 3$ were evaluated as retarded general development and 4 as normal development.

In the ophthalmology examination, biomicroscopy of $31(96.9 \%)$ patients was normal. In $1(3.1 \%)$ patient, bilateral aphakia and micro cornea were determined. Bilateral mixed type astigmatism was determined in $2(6.3 \%)$ patients and glaucomatous optic atrophy in $2(6.3 \%)$ patients. The findings of the ophthalmology examinations are shown in Table 3.

A significant positive correlation was determined between the GMFCS and BFMF scores $(r=0.636, p<0.001)$. The Kappa value was calculated and the overall agreement between the GMFCS and BFMF was fair (Kappa value $=0.288)$ (Table 4).

Table 3. Findings of the ophthalmology examinations

\begin{tabular}{lc}
\hline Ophthalmological findings & $\begin{array}{c}\text { Total, } \mathrm{n}=32 \\
\mathrm{n}(\%)\end{array}$ \\
\hline Biomicroscopic examination & \\
Normal & $31(96.9)$ \\
Bilateral aphakia & $1(3.1)$ \\
Fundus examination & \\
Normal & $25(78.1)$ \\
Unilateral optic atrophy & $2(6.3)$ \\
Bilateral optic atrophy & $3(9.4)$ \\
Glaucomatous optic atrophy & $2(6.3)$ \\
Strabismus & \\
Exotropia & $4(12.5)$ \\
Esotropia & $1(3.1)$ \\
Refraction errors & \\
Normal & $30(93.8)$ \\
Mixed type astigmatism & $2(6.3)$ \\
Right eye intraocular pressure, mean \pm SD & $15.65 \pm 3.37$ \\
(range), mmHg & $(11-30)$ \\
Left eye intraocular pressure, mean $\pm \mathrm{SD}$ & $15.81 \pm 3.45$ \\
(range), mmHg & $(11-31)$ \\
\hline
\end{tabular}

Table 2. Distribution of the patients according to the ADSI test

\begin{tabular}{lccccc}
\hline Total, $\mathrm{n}=25$ & ADSI-GD & ADSI-CC & ADSI-FM & ADSI-GM & ADSI-SC \\
\hline Normal, $\mathrm{n}(\%)$ & $10(40)$ & $12(48)$ & $9(36)$ & $5(20)$ & $12(48)$ \\
Retarded, $\mathrm{n}(\%)$ & $15(60)$ & $13(52)$ & $16(64)$ & $20(80)$ & $13(52)$ \\
\hline
\end{tabular}

ADSI: Ankara Developmental Screening Inventory, GD: general development, CC: communication-cognitive, FM: fine motor, GM: gross motor, SC: social skills-self-care 
1682 J. Phys. Ther. Sci. Vol. 26, No. 11, 2014

Table 4. Distribution of GMFCS and BFMF levels

\begin{tabular}{lcccccc}
\hline GMFCS & BFMF levels & \multicolumn{7}{l}{} \\
\cline { 2 - 7 } Levels & 1 & 2 & 3 & 4 & 5 & Total \\
\hline 1 & $13(40.6)$ & $3(9.4)$ & - & - & - & $16(50)$ \\
2 & $3(9.4)$ & $2(6.3)$ & - & - & - & $5(15.6)$ \\
3 & - & - & $1(3.1)$ & - & - & $1(3.1)$ \\
4 & $2(6.3)$ & $3(9.4)$ & $2(6.3)$ & $1(3.1)$ & $1(3.1)$ & $9(28.1)$ \\
5 & - & - & - & $1(3.1)$ & - & $1(3.1)$ \\
Total & $18(56.3)$ & $8(25)$ & $3(9.4)$ & $2(6.3)$ & $1(3.1)$ & $32(100)$ \\
\hline
\end{tabular}

Kappa: $0.288 \mathrm{p}=0.004$

BFMF: Bimanual Fine Motor Function, GMFCS: Gross Motor Function Classification System

Table 5. Distribution of GMFCS and MACS levels

\begin{tabular}{lcccccc}
\hline GMFCS & MACS levels & \multicolumn{7}{l}{} \\
\cline { 2 - 7 } Levels & 1 & 2 & 3 & 4 & 5 & Total \\
\hline 1 & $8(25)$ & $8(25)$ & - & - & - & $16(50)$ \\
2 & $2(6.3)$ & $3(9.4)$ & - & - & - & $5(15.6)$ \\
3 & - & - & $1(3.1)$ & - & - & $1(3.1)$ \\
4 & - & $6(18.8)$ & $1(3.1)$ & $1(3.1)$ & $1(3.1)$ & $9(28.1)$ \\
5 & - & $1(3.1)$ & - & - & - & $1(3.1)$ \\
Total & $10(31.3)$ & $18(56.3)$ & $2(6.3)$ & $1(3.1)$ & $1(3.1)$ & $32(100)$ \\
\hline
\end{tabular}

Kappa $=0.202$ p $=0.018$

GMFCS: Gross Motor Function Classification System, MACS: Manual Ability Classification System

Table 6. Distribution of BFMF and MACS levels

\begin{tabular}{lcccccc}
\hline BFMF & MACS levels & \multicolumn{7}{l}{} \\
\cline { 2 - 7 } levels & 1 & 2 & 3 & 4 & 5 & Total \\
\hline 1 & $10(31.3)$ & $8(25)$ & - & - & - & $18(56.3)$ \\
2 & - & $8(25)$ & - & - & - & $8(25)$ \\
3 & - & $1(3.1)$ & $2(6.3)$ & - & - & $3(9.4)$ \\
4 & - & $1(3.1)$ & - & $1(3.1)$ & - & $2(6.3)$ \\
5 & - & - & - & - & $1(3.1)$ & $1(3.1)$ \\
Total & $10(31.3)$ & $18(56.3)$ & $2(6.3)$ & $1(3.1)$ & $1(3.1)$ & $32(100)$ \\
\hline
\end{tabular}

Kappa $=0.537 \mathrm{p}<0.001$

BFMF: Bimanual Fine Motor Function, MACS: Manual Ability Classification System

A significant positive correlation was determined between the GMFCS and MACS scores ( $\mathrm{r}=0.553, \mathrm{p}=0.001)$. The Kappa value was calculated and the overall agreement between the GMFCS and MACS was fair (Kappa value $=0.202)$ (Table 5).

A significant positive correlation was determined between the MACS and BFMF scores $(r=0.718, p<0.001)$. The Kappa value was calculated and the overall agreement between the MACS and BFMF was moderate (Kappa val$\mathrm{ue}=0.537)$ (Table 6).

The relationships between ocular and oculomotor disorders, GMFCS, BFMF and MACS and daily life activities and quality of life are shown in Table 7 . The relationships between general development, ADSI evaluation, ocular and oculomotor disorders, GMFCS, BFMF and MACS and daily living activities and quality of life are shown in Table 8 .

\section{DISCUSSION}

This study found a significant relationship between developmental retardation in CP patients and disease severity, hand functions, daily living activities and quality of life. We also determined that MACS and BFMF conform with each other and with the severity of $\mathrm{CP}$, and that as $\mathrm{CP}$ severity increases, hand skills worsen.

It has been reported that BFMF is used more to define disability and MACS to evaluate activity although it is stated that it is difficult to compare these two scales ${ }^{26)}$. Another study reported a strong positive correlation between BFMF and MACS with good overall agreement ${ }^{10)}$. In the present study, a strong positive correlation was determined between BFMF and MACS. The overall agreement between MACS and BFMF was moderate. In addition, a strong correlation was found between GMFCS and BFMF, and GM- 
Table 7. Correlation among oculomotor disorders, GMFCS, BFMF and MACS, WeeFIM and quality of life

\begin{tabular}{llllllll}
\hline \multirow{2}{*}{ Total cases $(\mathrm{n}=32)$} & \multirow{2}{*}{ WeeFIM } & $\begin{array}{l}\text { PedsQL- } \\
\text { MTP-CF }\end{array}$ & $\begin{array}{c}\text { PedsQL- } \\
\text { PHTP-CF }\end{array}$ & $\begin{array}{c}\text { PedsQL- } \\
\text { PSHTP-CF }\end{array}$ & $\begin{array}{l}\text { PedsQL- } \\
\text { MTP-PF }\end{array}$ & $\begin{array}{c}\text { PedsQL- } \\
\text { PHTP-PF }\end{array}$ & $\begin{array}{c}\text { PedsQL- } \\
\text { PSHTP- }\end{array}$ \\
\hline GMFCS & $-0.802^{* *}$ & $-0.788^{* *}$ & $-0.836^{* *}$ & $-0.789^{* *}$ & $-0.788^{* *}$ & $-0.844^{* *}$ & $-0.710^{* *}$ \\
BFMF & $-0.769^{* *}$ & $-0.693^{* *}$ & $-0.661^{* *}$ & $-0.685^{* *}$ & $-0.729^{* *}$ & $-0.712^{* *}$ & $-0.668^{* *}$ \\
MACS & $-0.765^{* *}$ & $-0.806^{* *}$ & $-0.715^{* *}$ & $-0.803^{* *}$ & $-0.864^{* *}$ & $-0.765^{* *}$ & $-0.859^{* *}$ \\
Fundus pathology & -0.128 & -0.008 & -0.079 & -0.050 & -0.139 & -0.109 & -0.156 \\
Strabismus & -0.220 & -0.297 & -0.312 & -0.284 & -0.191 & -0.300 & -0.168 \\
\hline
\end{tabular}

**Correlation is significant at the 0.01 level (two-tailed)

BFMF: Bimanual Fine Motor Function, CF: Child form, MACS: Manual Ability Classification System, GMFCS: Gross Motor Function Classification System, MTP: measured total points, PF: Parent form, PedsQL: Paediatric Quality of Life Scale, PHTP: physical health total points, PSHTP: psychosocial health total points

Table 8. Correlation of the developmental level with oculomotor disorders, GMFCS, BFMF, MACS, WeeFIM and quality of life scores

\begin{tabular}{lcccccc}
\hline & $\begin{array}{c}\text { ADSI-GD } \\
\mathrm{n}=25\end{array}$ & $\begin{array}{c}\text { ADSI-CC } \\
\mathrm{n}=25\end{array}$ & $\begin{array}{c}\text { ADSI-FM } \\
\mathrm{n}=25\end{array}$ & $\begin{array}{c}\text { ADSI-GM } \\
\mathrm{n}=25\end{array}$ & $\begin{array}{c}\text { ADSI-SC } \\
\mathrm{n}=25\end{array}$ & $\begin{array}{c}\text { General } \\
\text { development } \\
\mathrm{n}=32\end{array}$ \\
\hline GMFCS & $0.612^{* *}$ & $0.756^{* *}$ & $0.556^{* *}$ & 0.262 & $0.756^{* *}$ & $0.518^{* *}$ \\
BFMF & $0.675^{* *}$ & $0.590^{* *}$ & $0.726^{* *}$ & 0.201 & $0.590^{* *}$ & $0.646^{* *}$ \\
MACS & $0.490^{*}$ & $0.468^{*}$ & $0.507^{* *}$ & 0.300 & $0.468^{*}$ & $0.537^{* *}$ \\
WeeFIM & $-0.700^{* *}$ & $-0.720^{* *}$ & $-0.691^{* *}$ & -0.279 & $-0.764^{* *}$ & $-0.645^{* *}$ \\
PedsQL- MTP-CF & $-0.645^{* *}$ & $-0.791^{* *}$ & $-0.552^{* *}$ & -0.296 & $-0.762^{* *}$ & $-0.669^{* *}$ \\
PedsQL- PHTP -CF & $-0.597^{* *}$ & $-0.768^{* *}$ & $-0.503^{* *}$ & -0.213 & $-0.711^{* *}$ & $-0.631^{* *}$ \\
PedsQL- PSHTP -CF & $-0.632^{* *}$ & $-0.802^{* *}$ & $-0.562^{* *}$ & -0.241 & $-0.768^{* *}$ & $-0.679^{* *}$ \\
PedsQL- MTP-PF & $-0.691^{* *}$ & $-0.789^{* *}$ & $-0.659^{* *}$ & -0.264 & $-0.756^{* *}$ & $-0.710^{* *}$ \\
PedsQL- PHTP -PF & $-0.743^{* *}$ & $-0.838^{* *}$ & $-0.657^{* *}$ & -0.215 & $-0.786^{* *}$ & $-0.754^{* *}$ \\
PedsQL- PSHTP -PF & $-0.573^{* *}$ & $-0.695^{* *}$ & $-0.642^{* *}$ & -0.236 & $-0.651^{* *}$ & $-0.629^{* *}$ \\
Fundus pathology & 0.134 & 0.201 & 0.327 & -0.055 & 0.201 & 0.010 \\
Strabismus & 0.000 & 0.080 & -0.042 & 0.000 & 0.080 & 0.033 \\
\hline
\end{tabular}

**Correlation is significant at the 0.01 level (two-tailed)

ADSI: Ankara Developmental Screening Inventory, BFMF: Bimanual Fine Motor Function, CC: communication-cognitive, CF: Child form, FM: fine motor, GD: general development, GM: gross motor, GMFCS: Gross Motor Function Classification System, MACS: Manual Ability Classification System, MTP: measured total points, PF: Parent form, PedsQL: Paediatric Quality of Life Scale, PHTP: physical health total points, PSHTP: psychosocial health total points, SC: social skills-self-care

FCS and MACS. The overall agreement was fair, a result that is consistent with previous studies ${ }^{10,26,27)}$. Although the corrrelations between the scales were high, the reason for low overall agreement, which was calculated using the Kappa statistic, is that the Kappa statistic is a method which is actually used in the evaluation of the same scale by two different researchers. For the evaluation of the agreement of two different scales, using the correlation coefficient is more appropriate ${ }^{25)}$. There is a lower rate of upper extremity involvement in children with $\mathrm{CP}$, so the low agreement found by the present study could be due to the evaluation of only diplegic $\mathrm{CP}$ children.

In the present study, a significant relationship was shown between all the subscales of the WeeFIM and PedsQL scales with each of the GMFCS, MACS and BFMF scales. In a study which evaluated the relationships between WeeFIM and GMFCS and MACS in spastic CP patients, significant correlations were determined between the latter two scales and WeeFIM, similar to the results of our present ${ }^{27)}$. As an explanation for these results, we consider that as $\mathrm{CP}$ sever- ity increases, hand functions are impaired with deteriorations in daily living activities and quality of life.

The visual process is a complex cerebral activity which involves a large part of the central nervous system ${ }^{28)}$. It can be considered, therefore that visual deficits are often seen in the neurodevelopmental disabilities which are observed in CP. In CP patients with hypoxic ischaemia encephalopathy, not only the motor pathways, but also the visual pathways are affected ${ }^{29)}$. Fundus pathologies associated with the trans-synaptic degeneration mechanism may develop in such patients ${ }^{30)}$. In support of this view, a MRI study of $\mathrm{CP}$ children with visual problems showed trans-synaptic degeneration of the lateral geniculate body ${ }^{31}$. Studies have also shown there is a relationship between the severity of visual sensory problems in children with $\mathrm{CP}$ and mental motor deficits $6,8,32)$. Therefore, early referral of $\mathrm{CP}$ children to an ophthalmologist can be an important factor in increasing mental and motor capacity. In the present study, fundus pathology was determined in $21.9 \%$, strabismus in $15.6 \%$ and refractive error in $6.3 \%$ of patients. However, no signifi- 
cant correlations were determined between the functional status, quality of life and developmental level of CP patients with fundus pathology or strabismus. Cerebral visual impairment is defined as the involvement of the retrogeniculate pathways in symptoms such as reduced visual field and visual acuity. It has been determined in $60-70 \%$ of children with $\mathrm{CP}^{33)}$. In the present study, cerebral visual impairment in children with CP was not evaluated. Therefore, a significant corrrelation may not have been revealed between oculomotor dysfunction and functional status, quality of life and developmental level in children without oculomotor dysfunction who may have visual problems.

In the present study, significant correlations were determined between general developmental level and the functional status and quality of life of the children. In children evaluated with the ADSI, significant relationships were also determined between functional status and quality of life and all the subscales of ADSI except the ADSI-GM subscale. The motivation of the children and general developmental levels may affect hand skills. Therefore, when there is a poor functional status in children with good general development and high capacity expectations, motivational factors can be considered to be exerting an effect and different treatment strategies should be defined.

Limitations of the present study were the inclusion of only diplegic type spastic CP patients, and the lack of evaluation of cerebral visual impairment, visuocognitive dysfunction or visuoperceptual diseases in the ophthalmology examination.

In conclusion, GMFCS, MACS and BFMF can be useful in the determination of the functional status of children with $\mathrm{CP}$ as they are easy, practical and simple classification scales which are consistent with each other. Ophthalmological examination of children with $\mathrm{CP}$ in the early period and early treatment strategies may enhance the possibility of increasing the mental and motor development of these children. However, there is a need for further larger studies with detailed neuro-ophthalmological evaluation including $\mathrm{CP}$ patients with different clinical characteristics.

\section{REFERENCES}

1) Song CS: Relationships between physical and cognitive functioning and activities of daily living in children with cerebral palsy. J Phys Ther Sci, 2013, 25: 619-622. [Medline] [CrossRef]

2) Rosenbaum P, Paneth N, Leviton A, et al.: A report: the definition and classification of cerebral palsy April 2006. Dev Med Child Neurol Suppl, 2007, 109: 8-14. [Medline]

3) Serdaroğlu A, Cansu A, Ozkan S, et al.: Prevalence of cerebral palsy in Turkish children between the ages of 2 and 16 years. Dev Med Child Neurol, 2006, 48: 413-416. [Medline] [CrossRef]

4) Odding E, Roebroeck ME, Stam HJ: The epidemiology of cerebral palsy: incidence, impairments and risk factors. Disabil Rehabil, 2006, 28: 183 191. [Medline] [CrossRef]

5) Pennefather PM, Tin W: Ocular abnormalities associated with cerebra palsy after preterm birth. Eye (Lond), 2000, 14: 78-81. [Medline] [CrossRef]

6) Black P: Visual disorders associated with cerebral palsy. Br J Ophthalmol, 1982, 66: 46-52. [Medline] [CrossRef]

7) Grether JK, Cummins SK, Nelson KB: The california cerebral palsy project. Paediatr Perinat Epidemiol, 1992, 6: 339-351. [Medline] [CrossRef]

8) Kozeis N, Anogeianaki A, Mitova DT, et al.: Visual function and visua perception in cerebral palsied children. Ophthalmic Physiol Opt, 2007, 27 44-53. [Medline] [CrossRef]

9) Ozturk AT, Berk AT, Yaman A: Ocular disorders in children with spastic subtype of cerebral palsy. Int J Ophthalmol, 2013, 6:204-210. [Medline]

10) Kurt EE, Unsal Delialioglu S, Ozel S, et al.: Evaluation of the relation between hand functions and severity of cerebral palsy. Turkiye Fiziksel Tip Ve Rehabilitasyon Dergisi-Turkish J Phys Med Rehabil, 2013, 59: 18-25.

11) Hagberg B, Hagberg G, Olow I: The changing panorama of cerebral palsy in Sweden 1954-1970. I. Analysis of the general changes. Acta Paediatr Scand, 1975, 64: 187-192. [Medline] [CrossRef]

12) Savasır I, Sezgin N, Erol N: Ankara developmental screening inventory [Ankara gelisim tarama envanteri-agte], 3rd ed. Ankara: Turkish psychology association Pub, 2005

13) Erol N, Sezgin N, Savașır I: Gelișim tarama envanteri ile ilgili geçerlik çalışmaları. Turk Psikoloji Dergisi, 1994, 8: 16-22.

14) Sezgin N, Erol N, Savaşır I: 0-6 yaş çocukları için gelişim tarama envanteri. Turk Psikiyatri Derg, 1993, 4: 9-17.

15) Palisano R, Rosenbaum $P$, Walter $S$, et al.: Development and reliability of a system to classify gross motor function in children with cerebral palsy. Dev Med Child Neurol, 1997, 39: 214-223. [Medline] [CrossRef]

16) Eliasson AC, Krumlinde-Sundholm L, Rösblad B, et al.: The Manual Ability Classification System (MACS) for children with cerebral palsy: scale development and evidence of validity and reliability. Dev Med Child Neurol, 2006, 48: 549-554. [Medline] [CrossRef]

17) Beckung E, Hagberg G: Neuroimpairments, activity limitations, and participation restrictions in children with cerebral palsy. Dev Med Child Neurol, 2002, 44: 309-316. [Medline] [CrossRef]

18) Ottenbacher KJ, Msall ME, Lyon NR, et al.: Interrater agreement and stability of the Functional Independence Measure for Children (WeeFIM): use in children with developmental disabilities. Arch Phys Med Rehabil, 1997, 78: 1309-1315. [Medline] [CrossRef]

19) Varni JW, Seid M, Rode CA: The PedsQL: measurement model for the pediatric quality of life inventory. Med Care, 1999, 37: 126-139. [Medline] [CrossRef]

20) Varni JW, Seid M, Kurtin PS: PedsQL 4.0: reliability and validity of the Pediatric Quality of Life Inventory version 4.0 generic core scales in healthy and patient populations. Med Care, 2001, 39: 800-812. [Medline] [CrossRef]

21) Eiser C, Morse R: Quality-of-life measures in chronic diseases of childhood. Health Technol Assess, 2001, 5: 1-157. [Medline]

22) Cakin Memik N, Ağaoğlu B, Coşkun A, et al.: [The validity and reliability of the Turkish Pediatric Quality of Life Inventory for children 13-18 years old]. Turk Psikiyatri Derg, 2007, 18: 353-363. [Medline]

23) Uneri OS, Agaoglu B, Coskun A, et al.: Validity and reliability of Pediatric Quality of Life Inventory for 2- to 4-year-old and 5- to 7-year-old Turkish children. Qual Life Res, 2008, 17: 307-315. [Medline] [CrossRef]

24) Memik NC, Agaoglu B, Coskun A, et al: Çocuklar İçin yaşam kalitesi ölçeğinin 8-12 yaş çocuk formunun geçerlik ve güvenirliği. Çocuk ve Ergen Ruh Sağlığı Dergisi, 2008: 87-98.

25) Altman DG: Practical statistics for medical research. London: Chapman and Hall, 1991

26) Carnahan KD, Arner M, Hägglund G: Association between gross motor function (GMFCS) and manual ability (MACS) in children with cerebral palsy. A population-based study of 359 children. BMC Musculoskelet Disord, 2007, 8: 50. [Medline] [CrossRef]

27) Gunel MK, Mutlu A, Tarsuslu T, et al.: Relationship among the Manual Ability Classification System (MACS), the Gross Motor Function Classification System (GMFCS), and the functional status (WeeFIM) in children with spastic cerebral palsy. Eur J Pediatr, 2009, 168: 477-485. [Medline] [CrossRef]

28) Dutton GN, McKillop EC, Saidkasimova S: Visual problems as a result of brain damage in children. Br J Ophthalmol, 2006, 90: 932-933. [Medline] [CrossRef]

29) Dutton GN, Jacobson LK: Cerebral visual impairment in children. Semin Neonatol, 2001, 6: 477-485. [Medline] [CrossRef]

30) Ruberto G, Salati R, Milano G, et al.: Changes in the optic disc excavation of children affected by cerebral visual impairment: a tomographic analysis. Invest Ophthalmol Vis Sci, 2006, 47: 484-488. [Medline] [CrossRef]

31) Uggetti C, Egitto MG, Fazzi E, et al.: Transsynaptic degeneration of lateral geniculate bodies in blind children: in vivo MR demonstration. AJNR Am J Neuroradiol, 1997, 18: 233-238. [Medline]

32) Ghasia F, Brunstrom J, Gordon M, et al.: Frequency and severity of visual sensory and motor deficits in children with cerebral palsy: gross motor function classification scale. Invest Ophthalmol Vis Sci, 2008, 49: 572 580. [Medline] [CrossRef]

33) Schenk-Rootlieb AJ, van Nieuwenhuizen O, van Waes PF, et al.: Cerebral visual impairment in cerebral palsy: relation to structural abnormalities of the cerebrum. Neuropediatrics, 1994, 25: 68-72. [Medline] [CrossRef] 